MATEC Web of Conferences 47, 04017 (2016)

DOI: $10.1051 /$ matecconf/20164704017

(C) Owned by the authors, published by EDP Sciences, 2016

\title{
Motivational Factors on Adopting Modular Coordination Concept in Industrialized Building System (IBS)
}

\author{
Riduan Yunus ${ }^{1,}$, , Azeanita Suratkon ${ }^{1}$, Mia Wimala ${ }^{2}$, Hazrul Abdul Hamid ${ }^{1}$ and Siti Rahimah Mohd \\ Noor $^{1}$ \\ ${ }^{1}$ Jamilus Research Centre, Universiti Tun Hussein Onn Malaysia, 83000 Parit Raja, Johor, Malaysia \\ ${ }^{2}$ Institut Teknologi Nasional Bandung, 40124 Bandung, Indonesia
}

\begin{abstract}
Modular coordination (MC) is recognized as a tool towards rationalization and industrialization. The implementation of MC concept in the design stage may improve the constructability and construction time. However, the implementation of MC in Industrialized Building System (IBS) implementation is still low compare to other developed countries such as the United Kingdom, Sweden and Japan. This paper examined the interrelationship between motivational factors of stakeholders in adopting MC concept using Interpretative Structural Modeling (ISM). Questionnaire survey was engaged in this study to identify significant motivational factors. Then, semi-structure interviews were used to collect qualitative data. ISM was adopted to build relationship between factors and develop an initial model to promote the adoption of MC in IBS construction. Seven (7) significant motivational factors were identified in this research namely 1) 'stakeholder's commitment', 2) 'reduce site disruption', 3) 'increase productivity', 4) 'high skilled workers', 5) 'site sustainability (environment, economy and social benefits)' 6) 'standardization' and 7) 'enabling 'open building' concept'. The result using Matrice d'Impacts Croises Multiplication Applique an Clasment (MICMAC) shows that there are three factors can be categorized as Independent / Driving Factors namely 'stakeholder's commitment', 'standardization' and 'enabling "open building" concept'. These factors should be explored in details to enhance the adoption of IBS in Malaysia. The findings provide a very good platform for a further research in formulating an efficient solution to promote MC concept adoption among the stakeholders. This scenario will improve the deliverables of IBS construction and eliminate negative perception in its implementation.
\end{abstract}

\section{Introduction}

The development of construction industry is rapid. Advanced technology and methods need to be integrated swiftly in order to compete in this industry. Malaysia as a developing country laid a comprehensive blue print in order to ensure the industry is competitive [1]. One of the strategies is to improve the adoption of Industrialized Building System (IBS). IBS have a potential to improve sustainability and keep the GDP of the country at the promising state [2-5]. However, the adoption of IBS in Malaysia is still low due to resistance towards change and lack of information to support the transformation [5]. Therefore, it is vital to identify the motivational factors to enhance the adoption of IBS.

\footnotetext{
${ }^{\text {a }}$ Corresponding author : riduan@uthm.edu.my
} 
Modular Coordination (MC) is a standard of measurement for IBS elements to coordinate the dimension and spaces. It is where a building and its components are being dimensioned and positioned in a basic unit or module known as $1 \mathrm{M}$ which is equivalent to $100 \mathrm{~mm}$. The implementation of $\mathrm{MC}$ concept towards design prefabricated components may enhance the total constructability in the construction project [6]. The modular is an intermediate stage towards an eventual evolvement of open system which allows for easy adaptation of prefabricated components to any layout and their interchangeability within the building. Malaysian Standard MS 1064 was introduced by the local Malaysia government to catalyze the development of IBS implementation.

Malaysian Standard MS 1064 was prefaced by Malaysia government which obligates architects, suppliers, and contractors to follow the standard of specification established for the size of fundamental modular unit [7]. However, the adoption of this standard is still low due to misconception and lack of motivation to use MC.

\section{IBS and Modular Coordination}

IBS is a construction system with a combination of components that promote simplification and minimise on-site work. IBS components are manufactured in a factory either on or off site. The components are then positioned and assembled into structures. The production in a controlled environment able to reduce the numbers of workers involved, shorten the construction period, increase quality of buildings, reduce cost and enhance occupational health and safety [8-10]. With the coordination for measurement system and open building concepts, this construction technique will improve the project deliverables.

Open building concept permits intercrossed applications. It is adaptable towards $\mathrm{MC}$ and standardization. Open building system enables the production of building components produce by various different factories. As the results, the products are compatible for any IBS's buildings even the components are supplied from different IBS's suppliers [8]. In order to objectify the implementation of open building system, the adoption of MC is vital as it is an international system of dimensional standardization in building.

MC usage is capable to be applied into a wide range of building technologies, ranging from component building through partial prefabrication to rationalized traditional building method. In additions, components which are coordination on a modular basic might be used in renovation programmers as well [11]. The coordination in components' dimension will allow the components to be used for any projects. However, open building system will also provide a high degree of design flexibility but required a maximum coordination between the designer and manufacturer [12]. Higher commitment is required in early involvement of project between key stakeholders [10].

\section{Research Method}

A combination of questionnaire survey and semi-structured interviews were adopted in this research. First, the questionnaire survey helps to identify significant motivational factors to adopt $\mathrm{MC}$ as a measurement concept. Then, semi-structured interviews assist researcher to understand the interrelationships between identified factors. Interpretive Structural Modeling (ISM) technique was used to build relationship between and develop model around the element of a system [13]. The ISM method was applied to identify interrelationships between identified significant factors. The interviewees provide information required by sharing their industrial experiences, appropriate judgments and suggestions. Semi-structured interviews are fit in exploring stakeholders' perception regarding industrial issues enabling information delivered to interviewer to develop a final model based findings. 


\section{Motivational Factors}

The survey investigated 18 motivational factors which were identified from literature review. The respondents were asked to rate the level of significance of each of these factors based on their judgment and experience. The respondents were divided into contractors, designers and manufacturers. The data was then analyzed by comparison and synthesis among others.

Table 1 summarizes the descriptive and inferential statistics for the "more" significant factors contributing to adoption of MC in IBS construction. Standard deviations show uniformity with all below 1, thus representing data accuracy in this research. The cut-off value in selecting the significant factors is 4.50 which indicate the factors are very significant. As a result, there are seven "very significant' motivational factors, namely 1) Reduce site disruption, 2) Enabling "open building" concept, 3) Increase productivity, 4) High skilled workers, 5) Site sustainability (environment, economy and social benefits), 6) Standardization and 7) Stakeholder's commitment.

Table 1. Ranking of motivational factors to adopt modular coordination.

\begin{tabular}{|l|l|c|c|c|c|c|}
\hline No. & \multicolumn{1}{|c|}{ Motivational Factors } & N & Minimum & Maximum & Mean & $\begin{array}{c}\text { Std. } \\
\text { Dev }\end{array}$ \\
\hline 1 & Reduce site disruption & 41 & 3 & 5 & 4.61 & 0.586 \\
\hline 2 & Enabling “Open building" concept & 41 & 3 & 5 & 4.59 & 0.547 \\
\hline 3 & Increase productivity & 41 & 3 & 5 & 4.59 & 0.631 \\
\hline 4 & High skilled workers & 41 & 3 & 5 & 4.59 & 0.591 \\
\hline 5 & $\begin{array}{l}\text { Site sustainability (environment, economy and } \\
\text { social benefits) }\end{array}$ & 41 & 3 & 5 & 4.56 & 0.634 \\
\hline 6 & Standardization & 41 & 3 & 5 & 4.54 & 0.552 \\
\hline 7 & Stakeholder's commitment & 41 & 3 & 5 & 4.51 & 0.597 \\
\hline 8 & Government support and policy & 41 & 3 & 5 & 4.49 & 0.553 \\
\hline 9 & Adaptability and buildability & 41 & 3 & 5 & 4.46 & 0.636 \\
\hline 10 & Open systems & 41 & 3 & 5 & 4.46 & 0.636 \\
\hline 11 & Local materials and availability & 41 & 2 & 5 & 4.46 & 0.711 \\
\hline 12 & Supplier competitiveness & 41 & 3 & 5 & 4.44 & 0.634 \\
\hline 13 & Efficiency in assembly and installation works & 41 & 3 & 5 & 4.44 & 0.634 \\
\hline 14 & $\begin{array}{l}\text { Sustainable procurement (e.g design charrette, } \\
\text { post-costruction or demolition consideration) }\end{array}$ & 41 & 2 & 5 & 4.41 & 0.741 \\
\hline 15 & Restricted on for IBS construction & 41 & 2 & 5 & 4.41 & 0.805 \\
\hline 16 & $\begin{array}{l}\text { Eliminated additional works and reduction of } \\
\text { waste generation }\end{array}$ & 41 & 3 & 5 & 4.39 & 0.666 \\
\hline 17 & Aesthetical value & 41 & 1 & 5 & 3.66 & 1.063 \\
\hline 18 & New innovation and creativity & 41 & 1 & 5 & 3.56 & 0.950 \\
\hline
\end{tabular}

\section{ISM Analysis and Results}

Analysis was conducted by using ISM method leads to several level of findings. The first analysis takes place in ISM is developing Structural self-interactive matrix (SSIM). The entire interviews were conducted by implementing face to face interview. Table 2 shows on how SSIM matrixes were developed by assigning value $\mathrm{V}, \mathrm{A}, \mathrm{X}$ or $\mathrm{O}$.

Table 2. The SSIM indicators relationship between variables.

\begin{tabular}{|c|c|c|}
\hline SSIM & $(\mathbf{i}, \mathbf{j})$ & Reachability Matrix \\
\hline V & Factor $\mathrm{i}$ will lead to Factor $\mathrm{j}$ & $\mathrm{e}_{\mathrm{ij}}=1$ while $\mathrm{e}_{\mathrm{ii}}=0$ \\
\hline $\mathrm{A}$ & Factor i will be achieved by Factor $\mathrm{j}$ & $\mathrm{e}_{\mathrm{ij}}=0$ while $\mathrm{e}_{\mathrm{ji}}=1$ \\
\hline $\mathrm{X}$ & Factor $\mathrm{i}$ and factor $\mathrm{j}$ will help achieve each other & $\mathrm{e}_{\mathrm{ij}}=1$ while $\mathrm{e}_{\mathrm{ii}}=1$ \\
\hline $\mathrm{O}$ & Factor I and factor $\mathrm{j}$ are not related & $\mathrm{e}_{\mathrm{ij}}=0$ while $\mathrm{e}_{\mathrm{ii}}=0$ \\
\hline
\end{tabular}


By understanding the guidelines in Table 2, the SSIM matrix was developed as shown in Table 3. This matrix then was converted into a binary matrix which then called as an initial reachability matrix (Table 4). The transitivity of the matrix was verified to establish the final reachability matrix (Table 5).

Table 3. Structural self-interactive matrix.

\begin{tabular}{|c|c|c|c|c|c|c|c|}
\hline No. & Factors & $\mathbf{7}$ & $\mathbf{6}$ & $\mathbf{5}$ & $\mathbf{4}$ & $\mathbf{3}$ & $\mathbf{2}$ \\
\hline 1 & Reduce site disruption & V & V & X & A & X & A \\
\hline 2 & Enabling “Open building" concept & A & X & V & O & V & \\
\hline 3 & Increase productivity & A & A & X & A & & \\
\hline 4 & High skilled workers & O & O & X & & & \\
\hline 5 & Site sustainability (environment, economy and social benefits) & A & A & & & & \\
\hline 6 & Standardization & A & & & & & \\
\hline 7 & Stakeholder's commitment & & & & & & \\
\hline
\end{tabular}

Table 4. Structural self-interactive matrix.

\begin{tabular}{|c|l|c|c|c|c|c|c|c|}
\hline No. & Factors & $\mathbf{1}$ & $\mathbf{2}$ & $\mathbf{3}$ & $\mathbf{4}$ & $\mathbf{5}$ & $\mathbf{6}$ & $\mathbf{7}$ \\
\hline 1 & Reduce site disruption & 1 & 0 & 1 & 0 & 1 & 0 & 0 \\
\hline 2 & Enabling “Open building" concept & 1 & 1 & 1 & 0 & 1 & 1 & 0 \\
\hline 3 & Increase productivity & 1 & 0 & 1 & 0 & 1 & 0 & 0 \\
\hline 4 & High skilled workers & 1 & 0 & 1 & 1 & 1 & 0 & 0 \\
\hline 5 & Site sustainability (environment, economy and social benefits) & 1 & 0 & 1 & 1 & 1 & 0 & 0 \\
\hline 6 & Standardization & 1 & 1 & 1 & 0 & 1 & 1 & 0 \\
\hline 7 & Stakeholder's commitment & 1 & 1 & 1 & 0 & 1 & 1 & 1 \\
\hline
\end{tabular}

Table 5. Final reachability matrix.

\begin{tabular}{|c|l|c|c|c|c|c|c|c|c|}
\hline No. & \multicolumn{1}{|c|}{ Factors } & $\mathbf{1}$ & $\mathbf{2}$ & $\mathbf{3}$ & $\mathbf{4}$ & $\mathbf{5}$ & $\mathbf{6}$ & $\mathbf{7}$ & $\begin{array}{c}\text { Driving } \\
\text { power }\end{array}$ \\
\hline 1 & Reduce site disruption & 1 & 0 & 1 & 1 & 1 & 0 & 0 & 4 \\
\hline 2 & Enabling "Open building" concept & 1 & 1 & 1 & 1 & 1 & 1 & 0 & 6 \\
\hline 3 & Increase productivity & 1 & 0 & 1 & 1 & 1 & 0 & 0 & 4 \\
\hline 4 & High skilled workers & 1 & 0 & 1 & 1 & 1 & 0 & 0 & 4 \\
\hline 5 & Site sustainability (environment, economy and social benefits) & 1 & 0 & 1 & 1 & 1 & 0 & 0 & 4 \\
\hline 6 & Standardization & 1 & 1 & 1 & 1 & 1 & 1 & 0 & 6 \\
\hline 7 & Stakeholder's commitment & 1 & 1 & 1 & 1 & 1 & 1 & 1 & 7 \\
\hline & Dependence & 7 & 3 & 7 & 7 & 7 & 3 & 1 & \\
\hline
\end{tabular}

The factors with the same reachability set and intersection set are located at the same level of the ISM hierarchy. The sets with the same reachability and intersection are given the top-level position as they will not help achieve any other variable above their own level [14]. Four iterations were conducted to allocate all factors in 3 levels (Table 6).

Table 6. Iteration for level partitions

\begin{tabular}{|c|l|c|c|c|c|}
\hline No. & \multicolumn{1}{|c|}{ Factors } & $\begin{array}{c}\text { Reachability } \\
\text { set }\end{array}$ & $\begin{array}{c}\text { Antecedent } \\
\text { set }\end{array}$ & $\begin{array}{c}\text { Intersection } \\
\text { set }\end{array}$ & Level \\
\hline 1 & Reduce site disruption & 1345 & 1234567 & 1345 & 1 \\
\hline 2 & Enabling "Open building" concept & 123456 & 267 & 26 & 2 \\
\hline 3 & Increase productivity & 1345 & 1234567 & 1345 & 1 \\
\hline 4 & High skilled workers & 1345 & 1234567 & 1345 & 1 \\
\hline 5 & $\begin{array}{l}\text { Site sustainability (environment, economy } \\
\text { and social benefits) }\end{array}$ & 1345 & 1234567 & 1345 & 1 \\
\hline 6 & Standardization & 1234567 & 267 & 267 & 2 \\
\hline 7 & Stakeholder's commitment & 1234567 & 7 & 7 & 3 \\
\hline
\end{tabular}


Based on the level partitions of the factors and the final reachability matrix, the final ISM based model was established (Figure 1).

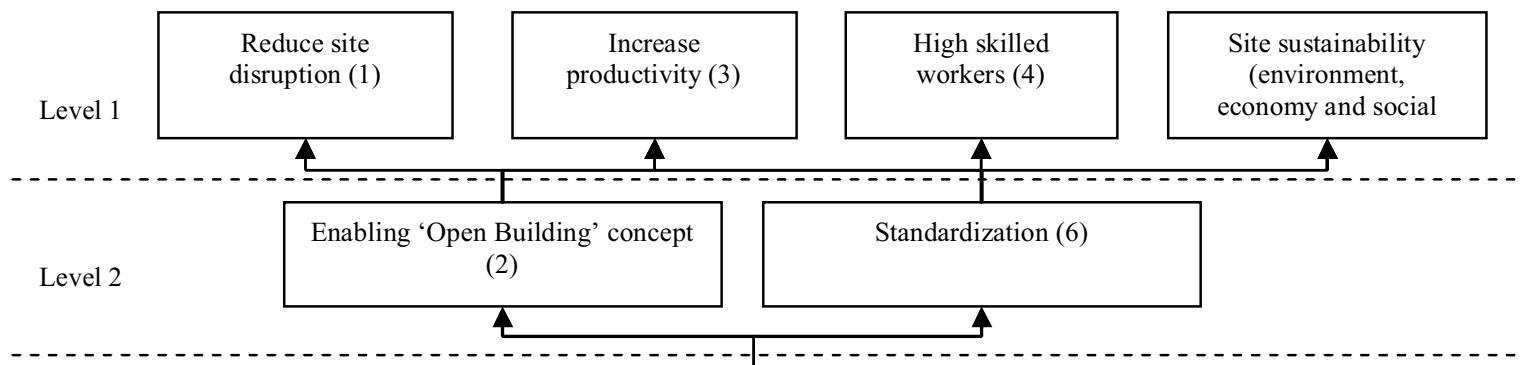

Level 3

(7) Stakeholder's commitment

Figure 1. ISM-based model of interrelations among significant motivational factors of adopting MC in IBS implementation.

The ISM model provides a visualized the motivational factors in adopting MC concepts in IBS implementation in a structured and systematic format. The results depict the interrelationships between the factors and their influence level in the system. It can be noted that the factors that related to benefits of MC concepts are located on the first level of the ISM model. These benefits only can be achieved if there are commitments from the stakeholders which relate to standardization and enabling the 'Open Building' concept.

\section{Matrice d'Impacts Croisés Multiplication Appliquée an Classment (MICMAC) Analysis}

MICMAC analysis is shown in Figure 2. The analysis helps to categorize the factors into a four different cluster, namely autonomous, dependent, linkage and independent.

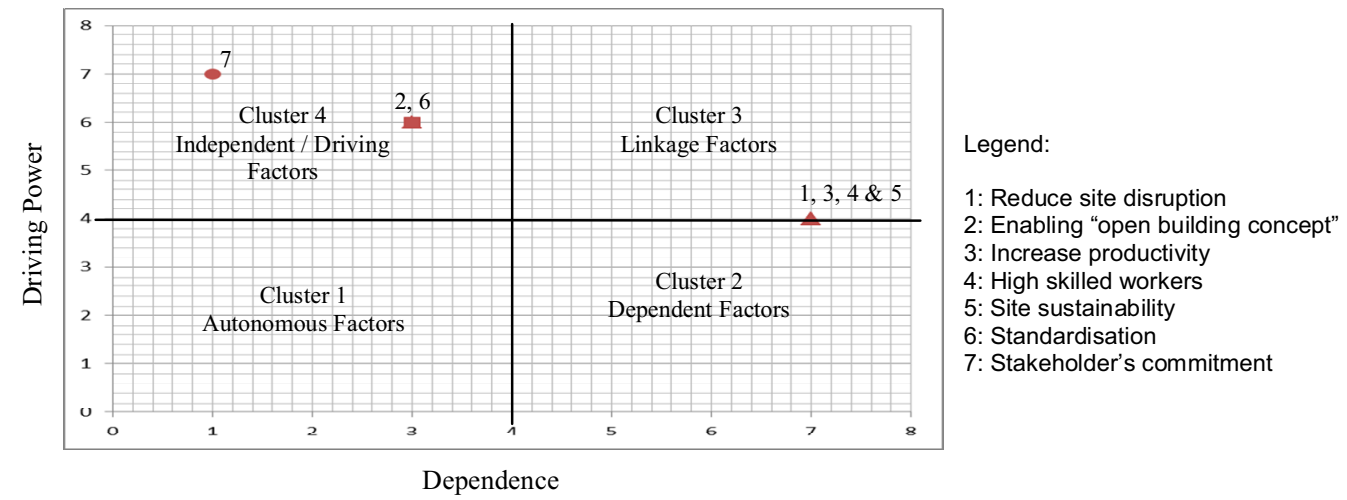

Figure 2. Driving power and dependence diagram.

The results confirmed that there are three factors can be clustered as independent or driving factors. The factors are 1) Stakeholder's commitment, 2) Enabling "Open building" concept and 3) Standardization. The analysis shows that these three factors are vital to ensure the successful of MC adoption. Thus, stakeholders are required to give more attention in getting all players participate in promoting MC. Local authorities should provide a strong fundamental to stakeholders by developing effective policies and legislative in implementing MC for IBS construction. On the other hand, 4 
factors are clustered in the middle of 2 (linkage factors) and 3 (dependent factors). The factors are 1) Reduce site disruption, 2) Increase productivity, 3) High skilled workers and 4) Site sustainability (environment, economy and social benefits). These factors are depending to the driving factors and linked to each other.

\section{Conclusions}

All stakeholders play important roles in promoting MC on the implementation of IBS in Malaysia. Several measures that should be taken include the establishment of policies and legislative associated to the promotion of $\mathrm{MC}$, development of standard for $\mathrm{MC}$, and empowerment of open building concept. In addition to the participation of stakeholders, there are some dependent factors that also need to be considered as motivational factors for adopting $\mathrm{MC}$ such as to reduce site disruption, increase the productivity, engage the high skilled workers, and support the site sustainability.

\section{References}

[1] Construction Industry Development Board Malaysia, Construction Industry Master Plan 20062015, Kuala Lumpur, (2006).

[2] Z. Abd Hamid, Industrialised building system (IBS) in Malaysia: The current state and R\&D initiatives, Malaysian Construction Research Journal, 1(2), 1-11, (2008).

[3] K.A.M. Kamar, Collaboration initiative on green construction and sustainability through industrialized buildings systems (IBS) in the Malaysian construction industry, International Journal of Sustainable Construction Engineering and Technology, 1(1), (2010).

[4] M.N.M. Nawi, A. Lee and K.M. Nor, Barriers to implementation of the industrialised building system (IBS) in Malaysia, The Built and Human Environment Review, 4, 22-35, (2011).

[5] R. Yunus and J. Yang, Improving ecological performance of industrialized building systems in Malaysia, Construction Management and Economics, 32(1-2),183-195, (2014).

[6] N.R.B. Zainol, A. Al-Mamun and P.Y. Permarupan, Overview of Malaysian modularity manufacturing practices, American Journal of Industrial and Business Management, 3(7), (2013).

[7] MS 1064, Guide to Modular Coordination in Building, Construction Industry Development Board Malaysia, (2001).

[8] N. Blismas and R. Wakefield, Drivers, constraints and the future of offsite manufacture in Australia, Construction Innovation: Information, Process, Management, 9(1), 72-83, (2009).

[9] L. Jaillon and C.S. Poon, Sustainable construction aspects of using prefabrication in dense urban environment: A Hong Kong case study, Construction Management and Economics, 26(9), 953 966, (2008).

[10]R. Yunus and J. Yang, Critical sustainability factors in industrialised building systems, Construction Innovation: Information, Process, Management, 12(4), 447 - 463, (2012).

[11]C.T. Haas and W.R. Fagerlund, Preliminary Research on Prefabrication, Preassembly, Modularization, an Offsite Fabrication in Construction: A Report to the Construction Industry Institute, University of Texas, (2002).

[12] J. Neelamkavil, Automation in the prefab and modular construction Industry, Proc. International Symposium on Automation and Robotics in Construction, Austin, (2009).

[13]L. Mei and J. Yang, Analysis of interrelationships between critical waste factors in office building retrofit projects using interpretive structural modelling, International Journal of Construction Management, 14(1), 15-27, (2014).

[14]S. Azevedo, H. Carvalho and V. Cruz-Machado, Using interpretive structural modelling to identify and rank performance measures: An application in the automotive supply chain, Baltic Journal of Management, . 8(2), 208-230, (2013). 